\title{
Tendências da literatura científica sobre genética de populações de plantas do Cerrado
}

\author{
Ueric José Borges de Souza ${ }^{1,4}$, Mariana Pires de Campos Telles ${ }^{1,3}$ e José Alexandre Felizola Diniz-Filho²
}

Recebido: 9.02.2016; aceito: 1.08.2016

\begin{abstract}
Trends in the scientific literature on population genetics of plants from Cerrado). The Cerrado biome is considered one of the biodiversity hotspots in the world, due to both the large extent of natural vegetation that has been continually lost and the high number of endemic plant species. It has often been listed as a priority in conservation programs and in population genetic studies. In order to determine trends in plant population genetic studies in this biome, a scientometric evaluation of published and available articles in different databases was performed. A total of 171 publications from 48 journals was found between the years 1999 and 2014, with the number of publications increasing significantly during this period. Ninety-one species with different life forms were studied, using different types of molecular markers. These analyses confer a better understanding of the current knowledge of plant population genetics in the Cerrado biome.
\end{abstract}

Keywords: scientometrics, genetic diversity, genetic divergence, molecular markers

RESUMO - (Tendências da literatura científica sobre genética de populações de plantas do Cerrado). O Cerrado é considerado um dos "hotspots" mundiais de biodiversidade, em função da grande extensão de vegetação natural que vem sendo continuamente perdida e do elevado número de espécies endêmicas de plantas, que muitas vezes têm sido listadas como prioridades em programas de conservação e para estudos de genética de populações. A fim de verificar tendências nos estudos de genética de populações das espécies de plantas deste bioma, uma avaliação cienciométrica dos artigos publicados e disponíveis em diferentes bases de dados foi realizada. Um total de 171 publicações provenientes de 48 periódicos foi encontrada, entre os anos de 1999 a 2014, com o número de publicações aumentando significativamente nesse período. Noventa e uma espécies com diferentes formas de vida foram estudadas, usando diferentes tipos de marcadores moleculares. A análise cienciometrica dos artigos encontrados permitiu uma melhor compreensão do conhecimento atual sobre a genética de populações de plantas do bioma Cerrado.

Palavras-chave: cienciometria, diversidade genética, divergência genética, marcadores moleculares

\section{Introdução}

O Cerrado, entre os seis biomas brasileiros, é o segundo maior em extensão, sendo superado apenas pela Amazônia, com uma área de aproximadamente 2 milhões de $\mathrm{km}^{2}$, o que representa cerca de $23 \%$ do território brasileiro (Bridgewater et al. 2004, Klink \& Machado 2005). Reconhecido como a savana mais rica do mundo, possui uma flora composta pelas mesmas famílias e muitos dos mesmos gêneros e espécies que ocorrem nas Florestas Atlântica e Amazônica, com composição florística variando de acordo com a localização geográfica e tipo de fitofisionomia (Méio et al. 2003, Bridgewater et al. 2004).
Dependendo do predomínio ou da proporção das diferentes formas de vida, bem como de sua densidade, caducidade foliar, entre outras características, diferentes estruturas e fitofisionomias são formadas, constituindo um complexo com diferentes formações vegetacionais (Coutinho 2006). No bioma Cerrado ocorrem formações vegetacionais que variam entre formações campestres, que compreendem o campo sujo, campo limpo e campo rupestre, formações florestais incluindo as matas de galeria, ciliares e secas e cerradão, e formações savânicas abrangendo o cerrado sentido restrito (cerrado denso, cerrado ralo, cerrado típico e cerrado rupestre), parque de cerrado, palmeiral (macaubal, guerobal, babaçual, e buritizal) e veredas (Ribeiro \& Walter 2008).

1. Universidade Federal de Goiás, Instituto de Ciências Biológicas, Laboratório de Genética \& Biodiversidade, Goiânia, GO, Brasil

2. Universidade Federal de Goiás, Instituto de Ciências Biológicas, Departamento de Ecologia, Goiânia, GO, Brasil

3. Pontifícia Universidade Católica de Goiás, Escola de Ciências Agrárias e Biológicas, Goiânia-GO, Brasil

4. Autor para correspondência: uericjose@gmail.com 
O Cerrado tem sido considerado como um dos hotspots mundiais de biodiversidade (Myers et al. 2000, Klink \& Machado 2005). Os hotspots são regiões que, por definição, apresentam um grande número de espécies endêmicas de plantas (no caso do Cerrado, espécies de plantas - riqueza $>1.500$ espécies) e que possuem uma distribuição restrita, o que as torna mais suscetíveis à extinção, já que são mais fortemente adaptadas às condições ambientais específicas, quando comparadas a espécies que apresentam distribuição ampla (Myers et al. 2000, Ferreira \& Boldrini 2011). Além disso, a elevada extensão de habitat natural, sendo continuamente perdida ( $<30 \%$ habitat remanescente), principalmente devido às ações humanas, pela conversão de florestas em campos de cultivo e pastagens (Klink \& Machado 2005, Giam et al. 2010).

Em função da grande diversidade de espécies, do alto nível de endemismo e da perda de habitat, há um interesse crescente em melhor estudar e compreender processos ecológicos e evolutivos atuando nas espécies com ocorrência neste bioma, de modo a buscar melhores estratégias de conservação. A análise genética com base em ferramentas moleculares pode auxiliar no entendimento da dinâmica populacional das espécies, fornecendo dados sobre diversos parâmetros evolutivos importantes, incluindo os níveis de variabilidade genética, a magnitude da distribuição desta variabilidade dentro e entre as populações, níveis de endogamia, taxa de fecundação cruzada e autofecundação, tamanho efetivo populacional e taxa de migração (Hedrick 2001, Agarwal et al. 2008, Eckert et al. 2010), bem como sobre processos históricos e padrões de distribuição no espaço geográfico em grandes escalas (Diniz-Filho et al. 2008, 2009). Todas essas informações podem ser utilizadas para o desenvolvimento de metodologias de modo a estabelecer estratégias de conservação in situ e ex situ e definir populações prioritárias para conservação com base em dados genético-moleculares (Diniz-Filho \& Telles 2002, Diniz-Filho et al. 2012).

Atualmente, existem muitas ferramentas moleculares para análise da variação genética de indivíduos em populações, e uma grande variedade de marcadores moleculares disponíveis para espécies vegetais. Dentre os principais tipos, destacam-se os, marcadores enzimáticos, cpDNA (cloroplastic DNA) (Atchison et al. 1976, Vedel et al. 1976), RFLP (Restriction Fragment Length Polymorphism) (Botstein et al. 1980), SSR (Simple Sequence Repeats) (Litt \& Luty 1989), RAPD (Random Amplified Polymorphic DNA) (Williams et al. 1990), SCAR
(Sequence Characterized Amplified Regions) (Paran \& Michelmore 1993), ISSR (Inter-SSR Amplification) (Zietkiewicz et al. 1994), SNPs (Single Nucleotide Polymorphisms) (Jordan \& Humphries 1994) e os AFLP (Amplified Fragment Length Polymorphism) (Vos et al. 1995). Estes marcadores diferem entre si pela região do genoma que permite acessar a informação, a quantidade de polimorfismo que pode ser detectado, abundância no genoma, especificidade em termos de localização no genoma, reprodutibilidade, metodologias de detecção e automação, além do custo que é bem variável (Ouborg et al. 1999, Schlötterer 2004, Agarwal et al. 2008).

As técnicas moleculares têm sido utilizadas rotineiramente para caracterizar os níveis de variabilidade genética (porcentagem de locos polimórficos, número de alelos por loco e heterozigosidade), bem como avaliar a estrutura genética nas populações de plantas do bioma Cerrado (Por exemplo: Collevatti et al. 2001a, Telles et al. 2003, Mendonça et al. 2012, Barbosa et al. 2015, Soares et al. 2015), utilizando-se da estatística $\mathrm{F}_{\mathrm{ST}}$, introduzida por Sewal Wright, (1951; ver Holsinger $\&$ Weir 2009) e seus análogos $\left(\mathrm{G}_{\mathrm{ST}}, \mathrm{R}_{\mathrm{ST}}, \theta_{\mathrm{P}}, \Phi_{\mathrm{ST}}\right)$. Outras abordagens, envolvendo técnicas de análise filogeográfica (Collevatti et al. 2012) e de estatística espacial (Por exemplo: Soares et al. 2008a, Collevatti et al. 2014, Lima et al. 2014, Telles et al. 2014, Soares et al. 2015), também têm sido utilizadas em tais estudos.

Considerando este aumento crescente no número de estudos utilizando técnicas moleculares e a possibilidade de melhor compreender processos microevolutivos atuando nas populações de espécies de plantas do bioma Cerrado, torna-se interessante a aplicação de uma abordagem cienciométrica a fim de reunir as publicações disponíveis e verificar tendências nessa área do conhecimento, com o intuito de contribuir para o direcionamento de novas pesquisas.

A cienciometria tem sido usada para avaliar aspectos quantitativos e qualitativos presentes na literatura em termos de ciência e inovação, sendo amplamente utilizada para explorar tendências em determinado campo de pesquisa (Carneiro et al. 2008, Nabout et al. 2010), para avaliar contribuições de um pesquisador em determinada disciplina ou conjunto de pesquisadores em determinada área (Wainer \& Vieira 2013), para comparar instituições de pesquisa ou países em relação à produção científica mundial (Coutinho et al. 2012, Almeida \& Guimarães 2013), ou quantificar o impacto de um artigo em particular (Carvalho et al. 2005). 
Assim, os principais objetivos deste trabalho foram verificar o número de artigos publicados na área de genética de populações de plantas, bem como a variação temporal sobre o número de artigos e a diversidade de revistas aonde estão sendo publicados os artigos sobre esse tema. Além disso, procurou-se identificar quais foram as espécies de plantas e famílias botânicas mais estudadas, algumas características da história de vida das espécies, bem com as ferramentas moleculares utilizadas para acessar os níveis de variabilidade genética nas populações.

\section{Material e métodos}

Foi realizada uma busca usando as bases de dados da 'Web-of-Science', 'Scielo', 'Scopus' e 'Google Scholar' utilizando como palavras-chaves o nome da espécie (Mendonça et al. 2008) combinado com o nome dos marcadores moleculares (e.g. "Dipteryx alata” AND RAPD OR Isoenzyme OR cpDNA OR AFLP OR ISSR OR SSR), entre os anos de 1999 e 2014. Como critério de inclusão foram considerados para as análises apresentadas aqui somente trabalhos que utilizaram técnicas moleculares e que continham medidas de diversidade e divergência genética em populações de espécies de plantas do Cerrado.

Para cada estudo de genética de populações incluído de acordo com os critérios acima, foram extraídas as seguintes informações: (i) periódico onde o artigo foi publicado, (ii) ano de publicação, (iii) instituição de pesquisa do primeiro autor, (iv) espécie estudada, (v) família botânica da espécie estudada e (vi) tipo de marcador molecular utilizado. Para cada espécie estudada nos trabalhos encontrados, também foi pesquisado a (vii) forma de vida (árvore, arbusto, subarbusto, erva e trepadeira) e (viii) fitofisionomia/ habitat (Mendonça et al. 2008). Adicionalmente, os estudos foram classificados de acordo com as metodologias de análises genético-populacionais utilizadas: (ix) estimador estatístico utilizado para quantificar a diferenciação genética entre populações $\left(\mathrm{F}_{\mathrm{ST}}, \mathrm{G}_{\mathrm{ST}}, \mathrm{R}_{\mathrm{ST}}, \theta_{\mathrm{P}}, \Phi_{\mathrm{ST}}\right),(\mathrm{x})$ método usado para gerar a matriz de distância genética e representar os padrões de divergência genética entre populações usando um dendograma (análise espacial implícita) e (xi) utilização de análises espaciais explícitas (e.g., teste de Mantel e autocorrelações espaciais).

O número de citações para cada publicação foi obtido utilizando o recurso de relatório de citações da base de dados Thomson 'ISI Web of Knowledge'. O Fator de Impacto (FI) das revistas aonde as publicações foram encontradas também foi incluído nas análises e foi obtido a partir do Journal of Citation Reports (JCR), publicado em 2014. O Fator de Impacto (FI) das revistas introduzido por Eugene Garfield e publicado anualmente no JCR é uma medida que tem sido usada para classificar e avaliar o desempenho das revistas científicas e como um substituto para verificar a qualidade e a importância do trabalho realizado por um pesquisador individual (Glänzel \& Moed 2002). O FI de determinada revista (X) no ano de $2012(t)$ é definido como o número de citações recebidas durante o ano de $2012(t)$ pelos artigos publicados em X nos anos de $2011(t-1)$ e $2010(t-2)$ divididos pelo número total de artigos publicados em $\mathrm{X}$ durante esses dois últimos anos (Glänzel \& Moed 2002). Para as análises do número de citação e fator de impacto das revistas, foram consideradas somente as publicações indexadas na 'Web of Science'.

A diversidade de revistas que publicaram trabalhos na área de genética de populações para espécies de plantas do Cerrado, em cada ano, foi estimada usando o índice de diversidade de ShannonWienner $\left(\mathrm{H}^{\prime}\right)$. Para avaliação na tendência temporal do número de artigos, o número de artigos obtidos em cada ano foi dividido pelo número total de artigos encontrados na base de dados do Thomson-ISI e esse valor foi multiplicado por 1.000, removendo assim o efeito da tendência geral de aumento no número de publicações científicas.

As análises dos dados obtidos foram realizadas utilizando-se análises de frequência simples. A tendência temporal na diversidade de revistas, em cada ano, bem como no número de publicações obtidas em cada ano, foram testadas utilizando-se a correlação de Pearson entre essas variáveis e o ano da publicação.

\section{Resultados}

A partir da busca nas bases de dados foi possível encontrar um total de 171 publicações entre os anos de 1999 a 2014 (anexo 1). O primeiro trabalho de genética de populações encontrado e publicado para espécies do Cerrado foi o de Collevati et al. (1999), com o desenvolvimento e caracterização de marcadores microssatélites para a espécie Caryocar brasiliense Cambess.

Após remoção da tendência geral de aumento no número de artigos, foi observado que o número de trabalhos na área de genética de populações envolvendo as espécies de plantas do Cerrado tem aumentado significativamente ao longo dos últimos $\operatorname{anos}(\mathrm{r}=0,694 ; \mathrm{P}<0,01$; figura 1$)$. 
Os artigos encontrados estão distribuídos em 48 revistas científicas diferentes. No entanto, 24 destas continham apenas um artigo, enquanto 13 revistas apresentaram um número superior ou igual a 5 artigos publicados, perfazendo um total de 116 artigos, o que corresponde a $67,84 \%$ do total. A revista Genetics and Molecular Research apresentou o maior número de publicações (21 ou 12,30\% do total de artigos), seguida pelas revistas Revista Brasileira de Botânica (13 ou 7,60\% do total de artigos), Scientia Forestalis (12 ou 7,00\% do total de artigos) e American Journal of Botany (11 ou 6,40\% do total de artigos) (figura 2). Também foi observado que a diversidade de revistas que publicam artigos sobre esse tema tem aumentado significativamente ao longo dos anos $(r=0,878$; $\mathrm{P}<0,01$; figura 3).

A distribuição do número de citações dos artigos encontrados foi fortemente assimétrica à direita, com $22,22 \%$ dos artigos nunca citados por nenhum outro trabalho. $\mathrm{O}$ artigo mais citado foi Collevati et al. (2001a), com 88 citações, e outros três artigos tiveram mais que 50 citações: Lacerda et al. (2001; 68 citações), Collevatti et al. (2001b; 55 citações) e Collevatti et al., (2003; 51 citações).

Dentre as revistas avaliadas, a que apresentou o maior fator de impacto foi a Molecular Ecology $(\mathrm{FI}=6,494)$, seguida pela Journal of Ecology $(\mathrm{FI}=5,521)$ e Evolution $(\mathrm{FI}=4,612)$. Ao se avaliar o valor médio do fator de impacto $(\mathrm{FI})$ das revistas $(1,796 ; \pm 0,235 \mathrm{SE})$, ano após ano, não foi verificado grande variação. O valor médio do FI encontrado para essas revistas está abaixo da média internacional para as revistas das áreas 'Plant Sciences' $(2,033 ; \pm$ $0,169 \mathrm{SE})$ e Genetics \& Heredity $(3,582 ; \pm 0,330 \mathrm{SE})$.

Considerando a instituição de pesquisa do primeiro autor, foi observado um predomínio de publicações por instituições de nacionalidade brasileira (169 ou 98,83\% do total de publicações), o que era esperado em se tratando de estudos com espécies com ocorrência no bioma Cerrado. Do total de 36 instituições, as que apresentaram o maior número de publicações foram, respectivamente, a Universidade Federal de Goiás ( 24 ou 14,0\%), a Escola Superior de Agricultura "Luiz de Queiroz" (17 ou 9,90\%), a Universidade Federal de Minas Gerais (17 ou 9,90\%) e a Empresa Brasileira de Pesquisa Agropecuária (16 ou 9,40\%; 5 publicações: Embrapa Cerrados, 4 publicações: CENARGEN, 1 publicação: Embrapa Agroenergia, Embrapa Agroflorestal, Embrapa MeioNorte, Embrapa Semiárido, Embrapa Soja, Embrapa Tabuleiros Costeiros e Embrapa Trigo). Desse total, 17

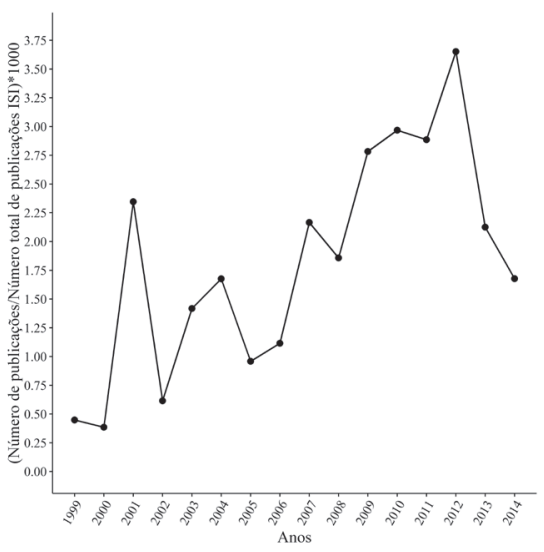

Figura 1. Variação temporal no número de publicações na área genética de populações para espécies de plantas do Cerrado entre os anos de 1999 a 2014.

Figure 1. Temporal variation of the number of publication for the subject population genetics refering to plant species of Cerrado. From 1999 to 2014.

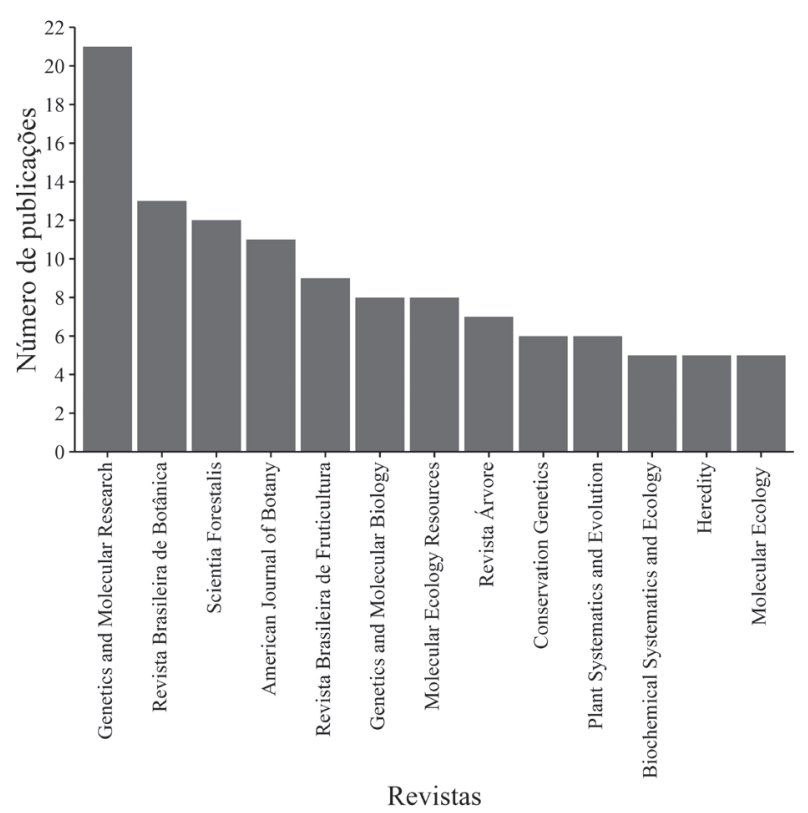

Figura 2. Revistas com maior número de publicações.

Figure 2. Number of publications per journal publishing about Cerrado plant species.

instituições foram representadas por apenas 1 publicação cada, e dentre estas, foram observadas instituições da Suíça (Conservatoire et jardin botaniques) (Caetano et al. 2008) e Espanhola (Universidade de Santiago de Compostela) (Silva et al. 2011), ambas com colaborações de instituições brasileiras.

Foram registrados dados para 91 espécies, abarcando 27 famílias botânicas, sendo as que apresentaram o maior número de espécies estudadas 
(figura 4) a Fabaceae Lindl. (20,90\% ou 19 espécies), a Asteraceae Bercht. \& Presl (9,90\% ou 9 espécies) e a Bignoniaceae Juss ( $8,80 \%$ ou 8 espécies). A maioria dos trabalhos apresenta dados para apenas uma espécie, e somente em 11 publicações duas ou mais espécies foram estudadas. Também foi observado que existe um baixo percentual de publicações para cada uma das espécies. Somente 15 espécies $(16,48 \%$ do total de espécies) foram representadas 4 ou mais vezes no conjunto de dados (figura 5), enquanto 58 foram estudadas apenas uma vez. As espécies Caryocar brasiliense (8 publicações: Collevatti et al. 1999, 2001a, 2001b, 2003, 2010, Collevatti \& Hay 2011, Melo Júnior et al. 2004, 2012), Eugenia dysenterica DC. (7 publicações: Telles et al. 2001, 2003, 2013, Trindade \& Chaves, 2005, Zucchi et al. 2002, 2003, 2005) e Dipteryx alata Vogel. (7 publicações: Soares et al. 2008a, 2008b, 2012, 2014, Tarazi et al. 2010, Collevatti et al. 2013, Telles et al. 2014) foram a espécies do Cerrado com maior número de publicações até o momento.

Das 91 espécies registradas nos artigos, em relação ao hábito, foi possível observar árvores $(51,6 \%)$, ervas $(17,6 \%)$, arbustos $(15,4 \%)$, subarbustos $(9,9 \%)$, e trepadeiras $(5,5 \%)$. Os principais tipos fitofisionômicos ou habitat que essas espécies ocorrem são: cerrado stricto sensu $(13,4 \%)$, cerradão $(11,6 \%)$ e mata de galeria $(11,2 \%)$.

Foram encontradas publicações usando marcadores microssatélites, cpDNA, isoenzimas, RAPDs, AFLPs e ISRRs (figura 6). Em 8 publicações, mais de um tipo de marcador foi utilizado simultaneamente, sendo ambos incluídos nas análises. O marcador microssatélite foi a classe mais frequentemente utilizada nos estudos (81 publicações ou 45,30\%), seguida pelo RAPD (40 publicações ou 22,30\%) e isoenzimas (33 publicações ou 18,40\%).

Considerando o uso dos marcadores moleculares ano a ano, os microssatélites foi a classe de marcador mais usada nos anos 2008, 2009, 2011 e 2012, o RAPD no ano de 2010 e isoenzimas no ano de 2003, 2004, 2006 e 2007 (figura 6). Em geral, ao longo dos anos foi possível observar um aumento na frequência de publicações com o uso dos marcadores, principalmente dos microssatélites (figura 6). Entretanto, também foi possível observar que outras classes de marcadores moleculares, ainda continuam sendo usadas nos estudos genético-populacionais de espécies de plantas do Cerrado (figura 6).

Do total de publicações usando marcadores microssatélites, $31(38,27 \%)$ foram trabalhos com o objetivo de desenvolvimento e caracterização e 8 $(9,88 \%)$ de transferibilidade entre espécies próximas do ponto de vista evolutivo. Assim, até o ano de 2014, existem marcadores microssatélites desenvolvidos/ transferidos disponíveis para 48 espécies do Cerrado (tabela 1). A maior parte destes trabalhos (14 ou $35,90 \%$ ) foi publicada no ano de 2012 e não foi observado aumento significativo destas publicações ao longo dos anos $(r=0,348$; figura 7$)$.

Os trabalhos publicados usando microssatélites se encontram distribuídas em 31 revistas. As revistas Genetics and Molecular Research (com 5 publicações de desenvolvimento de microssatélites, 3 de transferibilidade e 3 usando marcadores previamente transferidos ou 12,30\%), American Journal of Botany (com 11 publicações de desenvolvimento e caracterização de marcadores microssatélites ou 13,60\%) e Molecular Ecology Resources (com 6 publicações de desenvolvimento de marcadores e duas de transferibilidade ou 9,90\%), foram representadas respectivamente pelo maior número de publicações.

Em relação à nacionalidade das revistas que publicaram trabalhos usando microssatélites, foi observado que $77,40 \%$ são revistas internacionais ( 24 revistas), enquanto $22,60 \%$ são nacionais ( 7 revistas). Um maior número de publicações encontradas em revistas internacionais, também foi observado para os marcadores cpDNA (11 revistas, sendo 8 internacionais $(72,7 \%)$ e 3 nacionais $(27,3 \%)$ e ISSR (3 revistas, sendo 2 internacionais e 1 nacional). Já para os os marcadores RAPD (20 revistas, sendo $14(70,0 \%)$ nacionais e $6(30,0 \%)$ internacionais $)$, isoenzimas (15 revistas, sendo $9(60,0 \%)$ nacionais e $6(40,0 \%)$ internacionais) e AFLP (5 revistas, sendo $4(80,0 \%)$ nacionais e $1(20,0 \%)$ internacional) foi observado que a maioria das publicações são de revistas nacionais.

Em relação ao valor médio do fator de impacto das revistas ano a ano em relação aos marcadores moleculares, foi possível observar, considerando o primeiro e último ano em que foi encontrado publicações para cada marcador, uma redução do fator de impacto para todas as classes (figura 8). Isso foi notado principalmente para os trabalhos usando marcadores RAPD, em que o fator médio de impacto reduziu de 6,494 no ano de 2001 para 0,595 no ano de 2013 (figura 8). As publicações usando marcadores cpDNA e microssatélites foram publicada em revistas com maior fator de impacto, em relação às outras classes de marcadores ao longo dos anos. $\mathrm{E}$ de modo geral, publicações com essas duas classes 


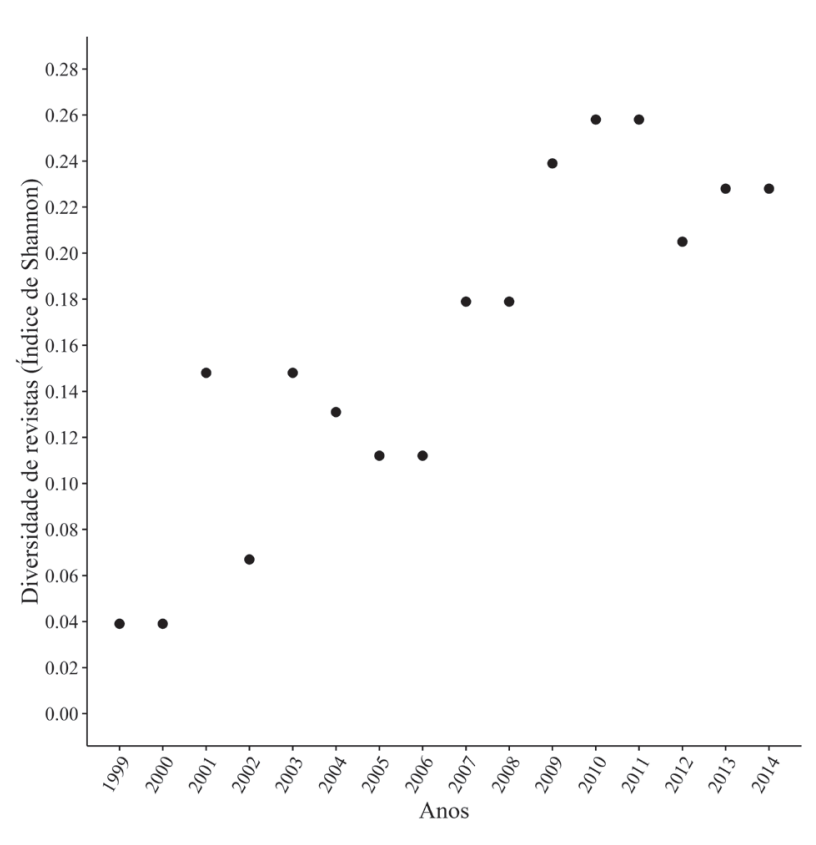

Figura 3. Diversidade de revistas que publicaram trabalhos na área de genética de populações de espécies de plantas do bioma Cerrado.

Figure 3. Diversity of journals publishing papers about population genetics of Cerrado plant species.

de marcadores também apresentaram maior fator de impacto médio, sendo 2,833 para cpDNA e 2,115 para microssatélites (tabela 2).

Pelo menos uma medida de diferenciação genética entre populações foi utilizada em 90 publicações, dentre os quais 18 utilizaram dois ou mais estimadores. Os estimadores mais utilizados foram o $\Phi_{\mathrm{ST}}(38,4 \%), \theta_{\mathrm{P}}(25,0 \%), \mathrm{G}_{\mathrm{ST}}(17,0 \%)$. Os padrões de divergência genética entre populações foram frequentemente analisados através de métodos de análises espaciais implícitas (agrupamento do tipo UPGMA), sendo a representatividade a partir de dendrogramas encontrada em 55 publicações, baseadas principalmente em Distâncias Genéticas de Nei $(38,2 \%)$ e Coeficiente de Jaccard (32,7\%). Análises espaciais explicitas foram frequentemente realizadas utilizando-se análise de autocorrelação espacial (27 publicações ou 15,79\%) e teste de Mantel (38 publicações ou 22,22\%).

\section{Discussão}

Aspectos cienciométricos - O número de estudos para as espécies de plantas do com foco em genética de populações durante o período de 1999 à 2014 aumentou linearmente. Este crescente interesse está diretamente relacionado com a ampla diversidade no número de espécies de plantas presente no bioma, bem como aos problemas que vem sendo enfrentado em relação à conservação da biodiversidade, dado principalmente pelo grau de perturbação e pressão antrópica nas áreas naturais de Cerrado. Além disso, há certamente aspectos relacionados à descentralização do conhecimento científico no país e à formação de grupos de pesquisa e programas de pós-graduação consolidados na região Centro-Oeste do Brasil (Coutinho et al. 2012).

A "qualidade" e relevância das revistas científicas são geralmente classificadas de acordo com fator de impacto, fornecido pelo Journal Citation Reports, na base de dados, 'Web of Science Thomson-ISI' (Institute for Scienfitic Information), o qual tem sido alvo de bastante controvérsia e também amplamente discutido na literatura, sendo defendida por alguns pesquisadores, com características positivas, bem como, algumas limitações sendo frequentemente descritas por outros (Pendlebury 2009, Balaban 2012). Uma tendência que tem sido observada é que artigos publicados em revistas científicas com alto fator de impacto tem maiores chances de serem lidos e posteriormente citados, em relação aos artigos publicados em revistas com menor fator de impacto (Balaban 2012). Essa foi uma tendência observada neste estudo em particular, no qual as duas publicações com o maior número de citações, foram publicadas na revista cientifica com o maior fator de impacto, dentre as revistas avaliadas neste estudo, inclusive superior em relação ao valor médio das revistas indexadas na área 'Genetics \& Heredity'.

O fator de impacto também tem sido utilizado por órgãos de fomento e avaliação da pós-graduação no Brasil, como a CAPES (Coordenação de Aperfeiçoamento de Pessoal de Nível Superior). A CAPES tem desempenhado um importante papel no desenvolvimento dos cursos de pós-graduação no Brasil e é, portanto, em grande parte, responsável por estimular o notável crescimento da produção científica nas últimas décadas no país. Algumas áreas de avaliação da CAPES têm utilizado o fator de impacto em uma escala decrescente de reclassificação das revistas científicas em diferentes estratos QUALIS (A1, A2, B1, B2, B3, B4, B5 e C) de modo a aferir a qualidade dos artigos e de outros tipos de produção científicas (Capes 2015) geradas pelos programas de pós-graduação. Essa reclassificação em diferentes QUALIS, tendo como critério o fator de impacto, tem gerado uma preocupação com o futuro das revistas científicas nacionais, pois muitas revistas brasileiras 
não estão indexadas ou foram indexadas recentemente no ISI, sendo classificadas em estratos inferiores, e pela utilização do fator de impacto publicado pelo JCR como único critério escolhido para acessar a qualidade das revistas científicas (Penteado-Filho 2009, Brazilian Editors 2010, Machado \& Zaher 2010, Rode 2010). Mais recentemente a nova área de "Biodiverisdade" (que inclui os programas de Pós-Graduação em Botânica, Zoologia, Ecologia e Oceanografia biológica) adotou critérios mais amplos, inclusive tentando equilibrar os fatores de impacto das diferentes áreas e subáreas dentro da área de avaliação, mas a Área de Ciências Biológicas I (que inclui os programas de genética) continua usando predominantemente o fator de impacto para montar o seu sistema QUALIS. Assim, as duas principais áreas temáticas da CAPES relacionadas à avaliação cienciométrica dos artigos utilizados no presente estudo adotam critérios distintos de classificação por "qualidade".

Grande parte das publicações encontradas foram desenvolvidas por instituições brasileiras e de ensino superior. De maneira geral a pesquisa científica no país é amplamente realizada dentro dos programas de pósgraduação stricto sensu localizada nas universidades (Coutinho et al. 2012). A produção científica do Brasil tem aumentado substancialmente, passando de aproximadamente 8.000 para 17.500 no período

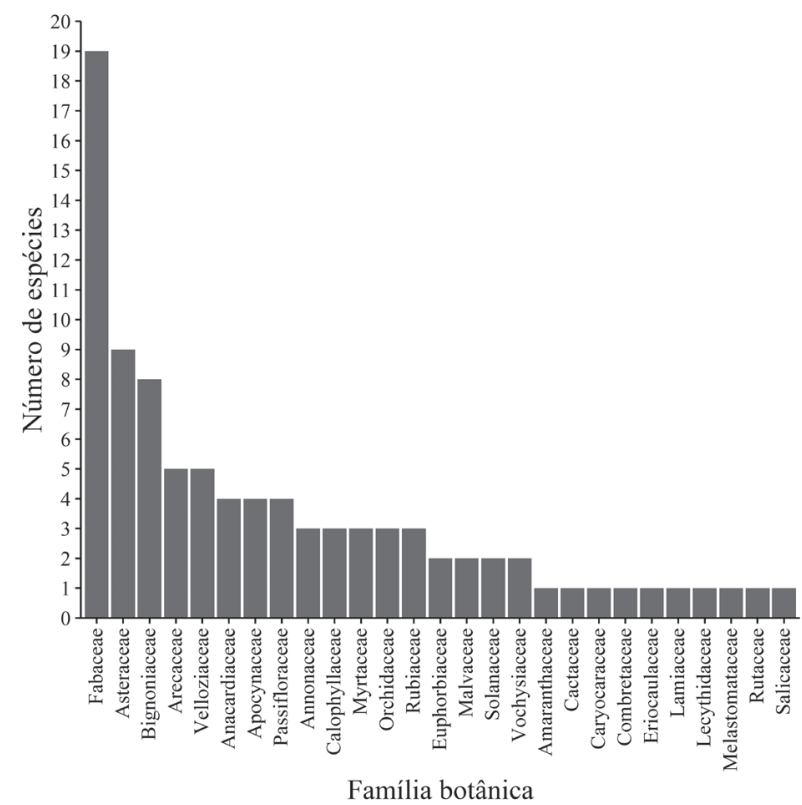

Figura 4. Família botânica das espécies encontrada nas publicações.

Figure 4. Taxonomical affiliation (Family) of the species in publications. de 1998 à 2007 (Adam \& King 2009). Sendo que, nos últimos 30 anos houve um crescimento médio de $10,7 \%$ ao ano, cerca de cinco vezes maior que a média mundial, ocupando o $13^{\circ}$ no ranking internacional (Almeida \& Guimarães 2013).

Desse modo, utilizando-se de uma abordagem cienciométrica, foi possível identificar importantes aspectos e tendências de publicações nos estudos de genética de populações de espécies de plantas do bioma Cerrado. Um aumento no número de publicações foi observado, demonstrando um crescente interesse de pesquisadores em estudar este bioma. Interesse principal dos programas de pós-graduação localizados nas instituições de ensino do país, sendo estas publicações direcionadas para revistas de nacionalidade brasileira, revelando a importância no uso de diferentes bases de dados, para o estudo em determinadas áreas de pesquisa. Assim, um progresso tem sido observado e o tema demonstra grande importância, com diversos estudos utilizando ferramentas moleculares sendo conduzidos e direcionados para o estabelecimento e desenvolvimento de estratégias de conservação dessas espécies

As espécies estudadas geneticamente no Cerrado A maioria das espécies foram representadas pela família Fabaceae, sendo está reconhecida como a

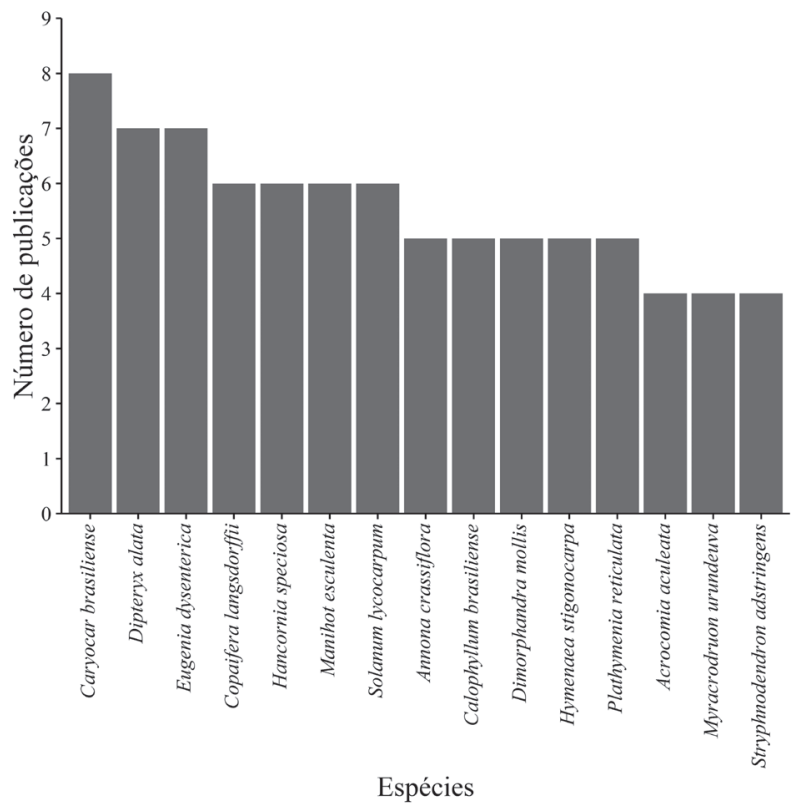

Figura 5. Espécies estudadas e encontradas em quatro ou mais publicações.

Figure 5. Species found in four or more publications. 
terceira maior entre as angiospermas no mundo, com aproximadamente 727 gêneros e 19.327 espécies (Lewis et al. 2005). Em diversos estudos de composição florística em diferentes fitofisionomias do bioma, está família tem sido relatada como uma das mais ricas em número de espécies (Moura et al. 2010, Silva \& Felfili 2012, Lima et al. 2015), inclusive, com grande potencial econômico, alimentício e para a produção de fármacos (Fernandes et al. 2010, Zimmermam-Franco et al. 2013, Prado et al. 2014).

Caryocar brasiliense foi a primeira espécie encontrada nas publicações (Collevatti et al. 1999) e com o maior número de estudos. A espécie C. brasiliense apresenta uma ampla distribuição no Cerrado, com ocorrência nos Estados de Goiás, Distrito Federal, Tocantins, São Paulo, Pará, Mato Grosso, Minas Gerais e Paraná, como também nos Estados nordestinos, Piauí, Ceará e Maranhão (Medeiros \& Amorim 2016), sendo comum nas fitofisionomias, cerradão, cerrado (stricto sensu), campo sujo, campo com murundus e carrasco (Mendonça et al. 2008, Medeiros \& Amorim 2016). Essa espécie tem considerável importância econômica devido à comercialização dos frutos e produtos derivados, com estudos sugerindo que em alguns municípios a comercialização do "Pequi" está abaixo de seu potencial de produção, sendo relacionado e justificado principalmente pelo baixo suporte por

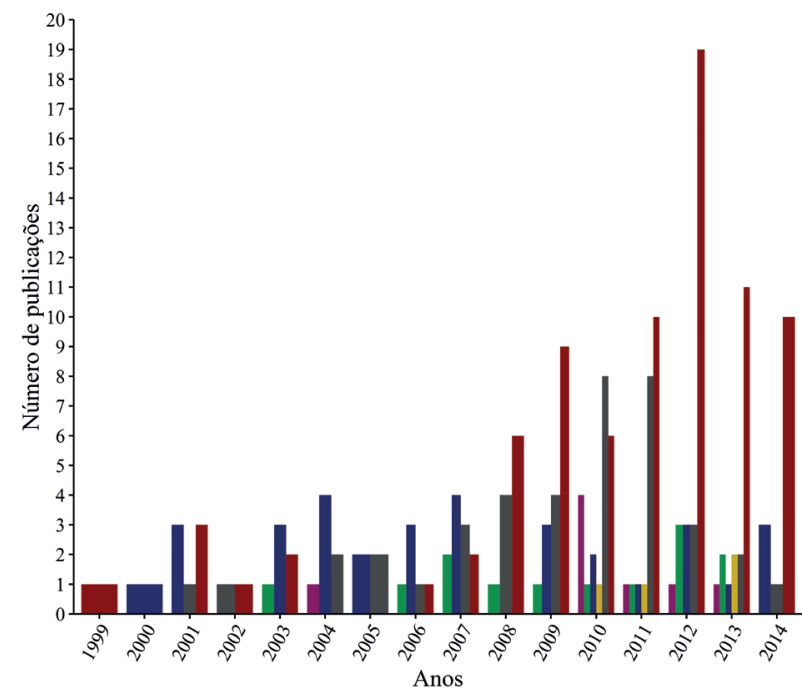

Figura 6. Número de publicações e os tipos marcadores utilizados entre o período de 1999 a 2014. AFLP, — Isoenzimas, RAPD, cpDNA, ISSR, SSR.

Figure 6. Number of publications and types of molecular markers used between the years 1999 and 2014. AFLP, Isoenzymes, RAPD, cpDNA, ISSR, ISSR. parte do governo local em se fazer da sua produção um investimento mais rentável, conforme outras espécies cultivadas (Nabout et al. 2011). E além do seu destaque como importante fonte de renda, o "pequi" também desempenha um importante papel nutricional para populações rurais em algumas regiões onde são produzidos, como fonte potencial de vitamina $\mathrm{A}, \mathrm{C}$ e E, assim como pelos teores de fibra alimentar e lipídeos e carotenoides (Lima et al. 2007, Cardoso et al. 2013).

Assumindo a classificação de Mendonça et al. (2008), as principais formas de vida das espécies estudadas foram árvores. Árvores apresentam grande importância econômica e são ecologicamente dominantes em diversos ecossistemas, sendo também mais fáceis de amostrar e de identificar em campo, o que pode explicar a predominância desproporcional (em relação à riqueza relativa de espécies) nos estudos genético-populacionais.

O cerrado stricto sensu foi o principal tipo fitofisionômico ou habitat das espécies estudadas. $\mathrm{O}$ cerrado stricto sensu ocupa aproximadamente 70\% do bioma Cerrado e se caracteriza pela presença de árvores baixas, inclinadas, tortuosas, com ramificações retorcidas e, geralmente, com evidências de queimadas. $\mathrm{O}$ estrato arbóreo cobre de 5 a $70 \%$ da área dependendo do subtipo do cerrado sensu stricto, ou seja, denso, típico, ralo e rupestre (Ribeiro $\&$ Walter 1998). Diversos estudos sobre a florística e fitossociologia nesta fitofisionomia têm demonstrado grande diversidade e heterogeneidade florística, determinadas principalmente por fatores edáficos, altitude, latitude, ocorrência e frequência de fogo e perturbações antrópicas (Felfili \& Fagg 2007, Felfili et al. 2008, Ribeiro \& Walter 2008).

Os estudos genéticos moleculares sobre padrões de variação genética e inferência de processos microevolutivos têm auxiliado a compreensão de questões importantes relacionados com características ecológicas e evolutivas das espécies e populações de plantas (Savolainen \& Pyhäjärvi 2007). Esses estudos têm sido realizados principalmente devido aos avanços da biologia molecular, com a introdução e desenvolvimento de novos tipos de marcadores moleculares, baseados em diferentes princípios técnicos laboratoriais e aplicações. No entanto, o número de estudos é relativamente baixo, considerando algumas classes de marcadores e também o número de espécies e populações, dado a riqueza de espécies de plantas no bioma. Esse fato pode estar diretamente relacionado com a disponibilidade dos marcadores 


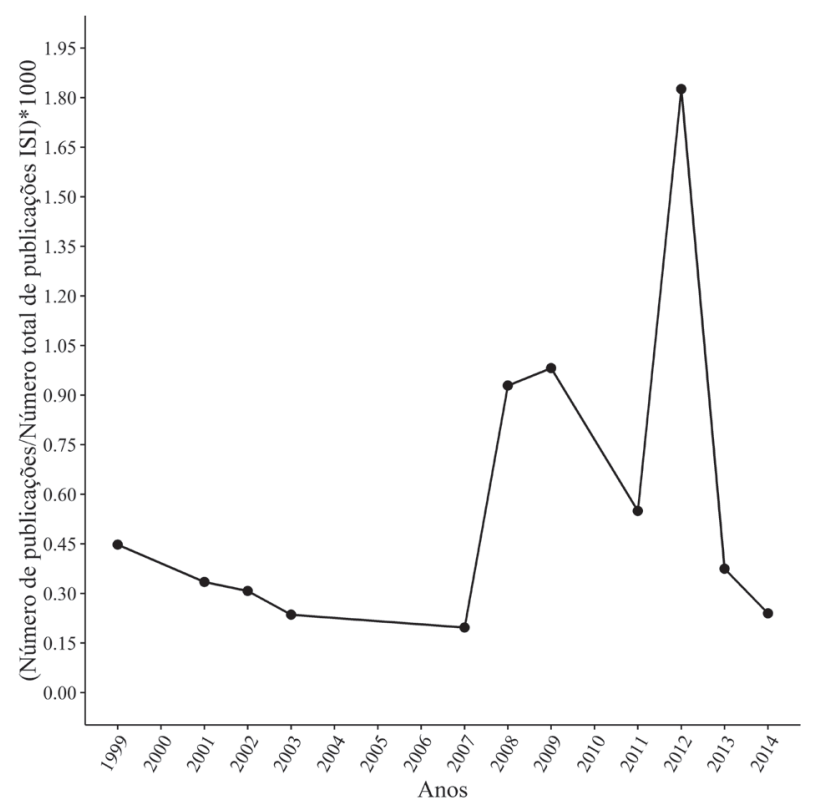

Figura 7. Variação temporal no número de publicações com o objetivo de desenvolver e transferir marcadores microssatélites entre os anos de 1999 a 2014.

Figure 7. Temporal variation in the number of publications dealing with development and transferability of microsatellites markers between 1999 and 2014.

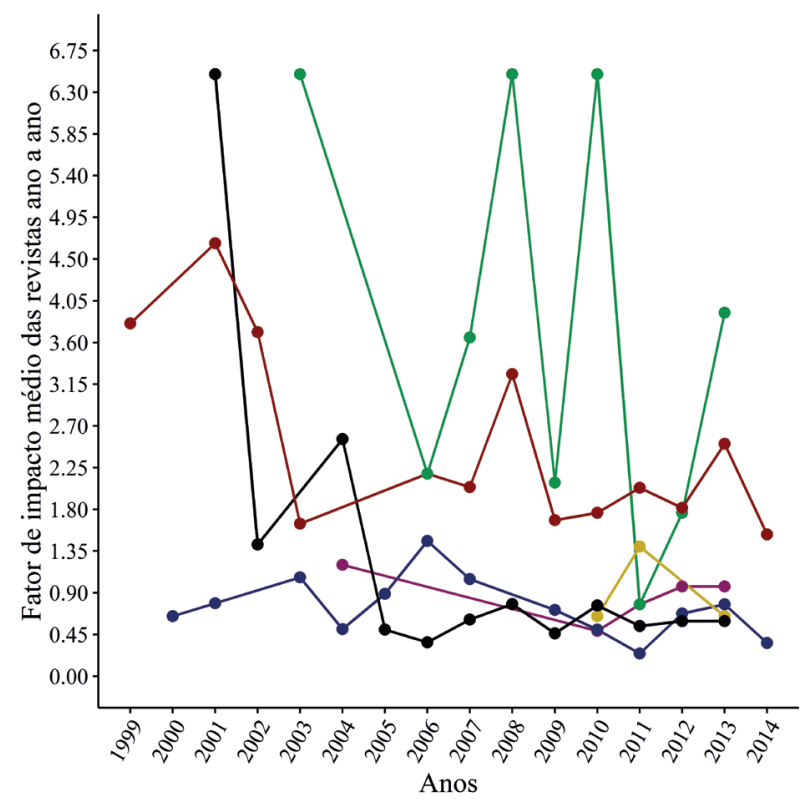

Figura 8. Variação temporal no fator de impacto médio das revistas em relação aos marcadores moleculares entre os anos de 1999 a $2014 .-$ AFLP, $\longrightarrow$ Isoenzimas, $\longrightarrow$ RAPD, --
cpDNA, - ISSR, $\longrightarrow$ SSR.

Figure 8. Temporal variation of journal impact factor average per molecular marker between 1999 and 2014. - - AFLP, $\longrightarrow$ Isoenzymes, $\longrightarrow$ RAPD, $\longrightarrow$ cpDNA, $\longrightarrow$ ISSR, - SSR. genéticos para a espécie que se pretende estudar. Para cada tipo de marcador molecular diferentes metodologias são empregadas, sendo muitas vezes necessária uma infraestrutura apropriada, variando de acordo com o tipo de marcador a ser utilizado, além do grande investimento financeiro muitas vezes envolvido, do nível de conhecimento necessário das técnicas moleculares e do genoma da espécie que se pretende estudar. A medida que esse conhecimento vai sendo adquirido, novas informações e aplicações vão sendo geradas para estabelecer e aumentar a eficiência dos programas de conservação com foco neste bioma.

No presente estudo é possível observar o aumento no uso dos marcadores microssatélites ao longo dos anos. Isso se deve principalmente, pela disponibilização e popularização das metodologias de desenvolvimento desse tipo de marcador que é espécie-específico, bem como pela possibilidade de transferibilidade desses marcadores entre espécies próximas do ponto de vista evolutivo. Além disso, de fato, essa classe de marcador tem considerável importância para os estudos genéticos por ser altamente variável, multialélico, codominante, pela abundância e ampla distribuição no genoma e por ser possível uma semi-automatização para a detecção por fluorescência em eletroforese capilar no sequenciador automático de DNA (Kalia et al. 2010).

Um dos métodos mais frequentemente utilizado para acessar a estrutura genética populacional é a estatística $\mathrm{F}_{\mathrm{ST}}$. Com o desenvolvimento de novas técnicas moleculares e ferramentas computacionais outras estatísticas análogas foram introduzidas para avaliar a estrutura genética das populações, assim, a porção da variabilidade genética que está no componente entre as populações também podem ser estimadas por $\mathrm{G}_{\mathrm{ST}}, \mathrm{R}_{\mathrm{ST}}, \theta_{\mathrm{P}}, \Phi_{\mathrm{ST}}$ (Holsinger \& Weir 2009). O estimador $\Phi_{\mathrm{ST}}$, proposto por Excoffier et al. (1992), foi o mais utilizado nas publicações encontradas para analisar a presença e o nível de diferenciação genética entre as populações de espécies de plantas do bioma Cerrado. Essas estatísticas que estimam a diferenciação genética entre populações têm uma relação com importantes processos microevolutivos (fluxo gênico, mutação e deriva genética). Populações grandes entre as quais há elevado fluxo gênico tenderão a exibir pouca diferenciação, enquanto populações pequenas entre as quais o fluxo gênico é restrito, tenderão a se diferenciar mais ao longo do tempo. Assim, $\mathrm{F}_{\mathrm{ST}}$ pode ser interpretado como uma medida desta diferenciação, sendo amplamente usado como estatística descritiva na genética de populações e evolução (Holsinger \& Weir 2009). 
Tabela 1. Espécies de plantas do Cerrado com marcadores microssatélites desenvolvidos/transferidos.

Table 1. Cerrado plant species with microsatellite markers developed /transferred.

\begin{tabular}{l}
\hline Espécies \\
\hline Acrocomia aculeata (Jacq.) Lodd. ex Mart \\
Aegiphila sellowiana Cham. \\
Anacardium humile A. St.-Hil. \\
Anadenanthera colubrina (Vell.) Brenan. \\
Annona coriacea Mart. \\
Annona crassiflora Mart. \\
Astronium urundeuva (Allemão) Engl. \\
Cariniana estrellensis (Raddi) Kuntze. \\
Caryocar brasiliense Cambess. \\
Casearia sylvestris Sw. \\
Centrosema pubescens Benth.
\end{tabular}

Copaifera langsdorffii Desf.

Cratylia mollis Mart. ex Benth.

Dimorphandra mollis Benth.

Dipteryx alata Vogel.

Enterolobium contortisiliquum (Vell.) Morong

Epidendrum denticulatum Barb. Rodr.

Eugenia dysenterica DC.

Eugenia uniflora $\mathrm{O}$. Berg

Euterpe edulis Mart.

Handroanthus chrysotrichus (Mart. ex A. DC.) Mattos

Handroanthus impetiginosus (Mart. ex A. DC.)

Mattos

Handroanthus serratifolius (Vahl) S.O. Grose

Himatanthus drasticus (Mart.) Plumel

Hymenaea courbaril L.

Hymenaea stigonocarpa Mart. ex Hayne

Jatropha curcas L.

Kielmeyera coriacea Mart. \& Zucc.

Kielmeyera grandiflora (Wawra) Saddi

Luehea divaricata Mart.

Lychnophora ericoides Mart.

Manihot esculenta Crantz

Mauritia flexuosa L. f.

Metrodorea nigra A. St.-Hil.

Myracrodruon urundeuva Allemão

Parapiptadenia rigida (Benth.) Brenan

Passiflora cincinnata Mast.

Plathymenia reticulata Benth.

Qualea grandiflora Mart.

Solanum crinitum Lam.

Solanum lycocarpum A. St.-Hil.

Stylosanthes capitata Vogel

Stylosanthes guianensis (Aubl.) Sw.
Publicações/Vide apêndice

Nucci et al. 2008, Abreu et al. 2012, Lanes et al. 2014

Ruas et al. 2011

Cota et al. 2012, Soares et al. 2013

Feres et al. 2012

Ribeiro et al. 2014

Pereira et al. 2008, Collevatti et al. 2014

Caetano et al. 2008

Guidugli 2009

Collevatti 1999, 2001a, 2001b, 2010, Collevatti \& Ray 2011

Cavallari 2010

Souza 2009

Martins 2008, Carvalho 2010, Tarazi et al. 2013a, Tarazi et al. 2013b, Antiqueira et al. 2014

López-Roberts et al. 2013

Souza et al. 2012

Tarazi et al. 2010, Soares et al. 2012, Collevatti et al. 2013, Telles et al. 2014

Moreira et al. 2012

Pinheiro et al. 2013

Zucchi et al. 2002, 2013, Telles et al. 2013

Ferreira-Ramos et al. 2008

Gaiotto et al. 2001, 2003

Collevatti et al. 2014

Collevatti et al. 2014

Collevatti et al. 2014

Baldauf et al. 2011, 2013, 2014

Ciampi et al. 2008, Feres et al. 2009

Moraes et al. 2007, Ciampi et al. 2008

Rosado et al. 2010, Bressan et al. 2012

Caddah et al. 2013

Caddah et al. 2013

Ruas et al. 2009

Rabelo et al. 2011

Siqueira et al. 2009, 2010, Mühlen et al. 2013

Menezes et al. 2012

Guidugli et al. 2012

Gaino et al. 2011

Costa et al. 2012

Cerqueira-Silva et al. 2012

Cruz et al. 2012, Oliveira et al. 2012

Ritter et al. 2012, Antiqueira et al. 2014, Buzzati et al. 2014

Moura et al. 2009

Martins et al. 2006, 2011, Moura et al. 2009, 2011, 2012, 2013

Santos et al. 2009, Santos-Garcia et al. 2011, 2012

Santos-Garcia et al. 2011 
Tabela 1 (continuação)

\begin{tabular}{|c|c|}
\hline \multicolumn{2}{|l|}{ Espécies } \\
\hline \multicolumn{2}{|c|}{$\begin{array}{l}\text { Stylosanthes macrocephala M. B. Ferreira \& S. } \\
\text { Costa }\end{array}$} \\
\hline \multicolumn{2}{|c|}{$\begin{array}{l}\text { Tabebuia aurea (Silva Manso) Benth. \& Hook. f. } \\
\text { ex S. Moore }\end{array}$} \\
\hline \multicolumn{2}{|c|}{ Tabebuia roseoalba (Ridl.) Sandwith } \\
\hline \multicolumn{2}{|c|}{ Tibouchina papyrus (Pohl) Toledo } \\
\hline \multicolumn{2}{|c|}{ Vellozia gigantea N.L. Menezes \& Mello-Silva } \\
\hline \multicolumn{2}{|c|}{$\begin{array}{l}\text { Tabela 2. Fator de impacto médio das revistas em relação } \\
\text { aos marcadores moleculares. }\end{array}$} \\
\hline \multicolumn{2}{|c|}{$\begin{array}{l}\text { Table } 2 \text {. Average impact factor of journals in relation to } \\
\text { molecular markers. }\end{array}$} \\
\hline Marcador & $\begin{array}{l}\text { Fator de impacto médio } \pm \text { Erro } \\
\text { padrão }\end{array}$ \\
\hline AFLP & $0,748 \pm 0,141$ \\
\hline cpDNA & $2,833 \pm 0,568$ \\
\hline Isoenzimas & $1,180 \pm 0,285$ \\
\hline ISSR & $1,005 \pm 0,218$ \\
\hline Microssatélites & $2,115 \pm 0,282$ \\
\hline RAPD & $1,203 \pm 0,327$ \\
\hline
\end{tabular}

Análises estatístico-espaciais implícitas (UPGMA) e explícitas (teste de Mantel e autocorrelações espaciais) também podem ser aplicadas a dados genéticos, obtidos via análise marcadores moleculares, foram utilizadas em algumas das publicações encontradas. A distância genética de Nei e o coeficiente de Jaccard têm sido utilizados pelos diferentes estudos encontrados, para inferir divergência genética entre populações. Os valores calculados de distância são empregados na construção de dendrogramas utilizando-se o método UPGMA, permitindo uma melhor visualização de forma hierárquica, pela formação de agrupamentos, da similaridade genética das populações. Por outro lado, o teste de Mantel tem sido utilizado para testar padrões de isolamento por distância, baseado na relação dos valores de diferenciação genética e distância geográfica. As análises de autocorrelações espaciais têm sido utilizadas para analisar a semelhança genética das populações vizinhas, considerando a distância geográfica, e como essa semelhança se altera a medida que se modifica a
Publicações/Vide apêndice

Santos-Garcia et al. 2009, 2012

Feres et al. 2009, Feres et al. 2012, Collevatti et al. 2014

Telles et al. 2011, Collevatti et al. 2012

Martins et al. 2012 escala geográfica (ver Diniz-Filho et al. 2013). Entretanto, é importante ressaltar que o número relativamente pequeno de estudos utilizando essas técnicas espacialmente explícitas $(<20 \%)$ está ligado ao pequeno número de populações analisados, o que torna mais difícil inferir processos evolutivos e ecológicos atuando nas populações e espécies (já que apenas estatísticas-F são em geral utilizadas, indicando apenas "diferença genética" entre as populações).

\section{Conclusões}

Neste estudo, utilizando-se de uma abordagem cienciométrica, foi possível identificar diversas tendências na literatura cientifica sobre genética de populações de plantas do Cerrado. Um aumento crescente e significativo no número de publicações foi observado, sendo estas realizadas principalmente por instituições brasileiras. Por outro lado, dada a riqueza de espécies no Cerrado, há relativamente poucas espécies estudadas, em função de diversas limitações e dificuldades envolvidas na obtenção dos marcadores genéticos para a espécie a ser estudada, bem como a logística de coleta das amostras biológicas necessárias para esse tipo de estudo. Na grande maioria dos estudos, árvores tem sido a principal forma de vida das espécies estudadas, explicado pela facilidade relativa de identificação e amostragem. Diferentes tipos de marcadores moleculares têm sido utilizados, com o aumento crescente principalmente dos marcadores microssatélites. Diferentes análises estatísticas têm sido conduzidas nos estudos, o que está diretamente relacionado com o conteúdo de informação gerado por cada tipo de marcador. Assim, poucas espécies do bioma foram estudadas em nível genéticopopulacional, representando uma oportunidade de estudos para grupos de pesquisa em todo o país. 


\section{Literatura citada}

Adams, J. \& King, C. 2009. The new geography of science: Research and collaboration in Brazil. Global research report. Thomson Reuters. Disponível em http:// researchanalytics.thomsonreuters.com/grr/ (acesso em 03-VIII-2015).

Agarwal, M., Shrivastava, N. \& Padh, H. 2008. Advances in molecular marker techniques and their applications in plant sciences. Plant Cell Reports 27: 617-631.

Almeida, E.C.E. \& Guimarães, J.A. 2013. Brazil's growing production of scientific articles-how are we doing with review articles and other qualitative indicators? Scientometrics 97: 287-315.

Atchison, B.A., Whitefield, P.R. \& Bottomley, W. 1976. Comparison of chloroplast DNAs by specific fragmentation with EcoRI endonuclease. Molecular and General Genetics 148: 263-269.

Balaban, A.T. 2012. Positive and negative aspects of citation indices and journal impact factors. Scientometrics 92: 241-247.

Barbosa, A.C.D.O.F., Collevatti, R.G., Chaves, L.J., Guedes, L.B.S., Diniz-Filho, J.A.F. \& Telles, M.P.C. 2015. Range-wide genetic differentiation of Eugenia dysenterica (Myrtaceae) populations in Brazilian Cerrado. Biochemical Systematics and Ecology 59: 288-296.

Botstein, D., White, R.L., Skolnick, M. \& Davis, R.W. 1980. Construction of a genetic linkage map in man using restriction fragment lenght polymorphisms. American Journal of Human Genetics 32: 314-331.

Brazilian Editors. 2010. Classification of jounals in the QUALIS system of CAPES - URGENT need of changing the criteria! Arquivos Brasileiros de Cardiologia 94: 290-291.

Bridgewater, S., Ratter, J.A. \& Ribeiro, J.F. 2004. Biogeographic patterns, $\beta$-diversity and dominance in the Cerrado biome of Brazil. Biodiversity and Conservation 13: 2295-2318.

Caetano, S., Prado, D., Pennington, R.T., Beck, S., Oliveira-Filho, A., Spichiger, R. \& Naciri, Y. 2008. The history of Seasonally Dry Tropical Forests in eastern South America: Inferences from the genetic structure of the tree Astronium urundeuva (Anacardiaceae). Molecular Ecology 17: 3147-3159.

Capes. 2015. Portal de Periódicos da Capes - Qualis Periódicos. Disponível em http://www.capes.gov.br/ avaliacao/qualis. (acesso em 05-VIII-2015).

Cardoso, L.M., Reis, B.D.L., Hamacek, F.R. \& Pinheiro Sant'ana, H.M. 2013. Chemical characteristics and bioactive compounds of cooked pequi fruits (Caryocar brasiliense Camb.) from the Brazilian Savannah. Fruits 68: 3-14.

Carneiro, F.M., Nabout, J.C. \& Bini, L.M. 2008. Trends in the scientific literature on phytoplankton. Limnology 9: 153-158.
Carvalho, P., Diniz-Filho, J.A.F. \& Bini, L.M. 2005. The impact of Felsenstein's "Phylogenies and the comparative method" on evolutionary biology. Scientometrics 62: 53-66.

Collevatti, R.G., Brondani, R.P.V \& Grattapaglia, D. 1999. Development and characterization of microsatellite markers for genetic analysis of a Brazilian endangered tree species Caryocar brasiliense. Heredity 83: 748-756.

Collevatti, R.G., Grattapaglia, D. \& Hay, J.D. 2001a. Population genetic structure of the endangered tropical tree species Caryocar brasiliense, based on variability at microsatellite loci. Molecular Ecology 10: 349-356.

Collevatti, R.G., Grattapaglia, D. \& Hay, J.D. 2001 b. High resolution microsatellite based analysis of the mating system allows the detection of significant biparental inbreeding in Caryocar brasiliense, an endangered tropical tree species. Heredity 86: 60-67.

Collevatti, R.G., Grattapaglia, D. \& Hay, J.D. 2003. Evidences for multiple maternal lineages of Caryocar brasiliense populations in the Brazilian Cerrado based on the analysis of chloroplast DNA sequences and microsatellite haplotype variation. Molecular Ecology 12: $105-115$.

Collevatti, R.G., Estolano, R., Garcia, S.F. \& Hay, J.D. 2010. Short-distance pollen dispersal and high selfpollination in a bat-pollinated neotropical tree. Tree Genetics and Genomes 6: 555-564.

Collevatti, R.G. \& Hay, J.D. 2011. Kin structure and genotype-dependent mortality: A study using the neotropical tree Caryocar brasiliense. Journal of Ecology 99: 757-763.

Collevatti, R.G., Castro, T.G., Lima, J.S. \& Telles, M.P.C. 2012. Phylogeography of Tibouchina papyrus (Pohl) Toledo (Melastomataceae), an endangered tree species from rocky savannas, suggests bidirectional expansion due to climate cooling in the Pleistocene. Ecology and Evolution 2: 1024-1035.

Collevatti, R.G., Telles, M.P.C., Nabout, J.C., Chaves, L.J. \& Soares, T.N. 2013. Demographic history and the low genetic diversity in Dipteryx alata (Fabaceae) from Brazilian Neotropical savannas. Heredity 111: 97-105.

Collevatti, R.G., Telles, M.P.C., Lima, J.S., Gouveia, F.O. \& Soares, T.N. 2014. Contrasting spatial genetic structure in Annona crassiflora populations from fragmented and pristine savannas. Plant Systematics and Evolution 300: 1719-1727.

Coutinho, L.M. 2006. O conceito de bioma. Acta Botanica Brasilica 20: 13-23.

Coutinho, R.X., Dávila, E.S., Santos, W.M., Rocha, J.B. T., Souza, D.O.G., Folmer, V. \& Puntel, R.L. 2012. Brazilian scientific production in science education. Scientometrics 92: 697-710. 
Diniz-Filho, J.A.F. \& Telles, M.P.C. 2002. Spatial autocorrelation analysis and the identification of operational units for conservation in continuous populations. Conservation Biology 16: 924-935.

Diniz-Filho, J.A.F., Telles, M.P., Bonatto, S.L., Eizirik, E., Freitas, T.R.O., De Marco Junior, P., Santos, F. R., Sole-Cava, A. \& Soares, T.N. 2008. Mapping the evolutionary twilight zone: molecular markers, populations and geography. Journal of Biogeography 35: 753-763.

Diniz-Filho, J.A.F., Nabout, J.C., Telles, M.P.C., Soares, T. N. \& Rangel, T.F.L.V.B. 2009. A review of techniques for spatial modeling in geographical, conservation and landscape genetics. Genetics and Molecular Biology 32: 203-211.

Diniz-Filho, J.A.F., Melo, D.B., Oliveira, G., Collevatti, R.G., Soares, T.N., Nabout, J.C., Lima, J.S., Dobrovolski, R., Chaves, L.J., Naves, R.V., Loyola, R.D. \& Telles, M.P.C. 2012. Planning for optimal conservation of geographical genetic variability within species. Conservation Genetics 13: 1085-1093.

Diniz-Filho, J.A.F., Soares, T.N., Lima, J.S., Dobrovolski, R., Landeiro, V.L., Telles, M.P.C., Rangel, T.F.L.V.B. \& Bini, L.M. 2013. Mantel test in population genetics. Genetics and Molecular Biology 36: 475-485.

Eckert, C.G., Kalisz, S., Geber, M.A., Sargent, R., Elle, E., Cheptou, P-O., Goodwillie, C., Johnston, M.O., Kelly, J.K., Moeller, D.A., Porcher, E., Ree, R.H., Vallejo-Marín, M. \& Winn, A.A. 2010. Plant mating systems in a changing world. Trends in Ecology \& Evolution 25: 35-43.

Excoffier, L., Smouse, P.E. \& Quattro, J.M. 1992. Analysis of molecular variance inferred from metric distances among DNA haplotypes: application to human mitochondrial DNA restriction data. Genetics 131: 479-491.

Felfili, J.M. \& Fagg, C.W. 2007. Floristic composition, diversity and structure of the "cerrado" sensu stricto on rocky soils in northern Goiás and southern Tocantins, Brazil. Revista Brasileira de Botânica 30: 375-385.

Felfili, J.M., Felfili, M.C., Nogueira, P.E., Armas, J.P.S., Farinas, M.R., Nunes, M., Silva Júnior, M. C.S., Rezende, A.V. \& Fagg, C.W. 2008. Padrões fitogeográficos e sua relação com sistemas de terra no Bioma Cerrado. In: S.M. Sano, S.P. Almeida \& J.F Ribeiro (ed.). Cerrado: ecologia e flora. Brasília: Embrapa Informação Tecnológica, pp. 214-228.

Fernandes, D.C., Freitas, J.B., Czeder, L.P. \& Naves, M.M.V. 2010. Nutritional composition and protein value of the baru (Dipteryx alata Vog.) almond from the Brazilian Savanna. Journal of the Science of Food and Agriculture 90: 1650-1655.

Ferreira, P.M.A. \& Boldrini, I.I. 2011. Potential reflection of distinct ecological units in plant endemism categories. Conservation Biology 25: 672-679.
Giam, X., Bradshaw, C.J.A., Tan, H.T.W. \& Sodhi, N.S. 2010. Future habitat loss and the conservation of plant biodiversity. Biological Conservation 143: 1594-1602.

Glänzel, W. \& Moed, H. 2002. Journal impact measures in bibliometric research. Scientometrics 53: 171-193.

Hedrick, P.W. 2001. Conservation genetics: where are we now? Trends in Ecology \& Evolution 16: 629-636.

Holsinger, K.E. \& Weir, B.S. 2009. Genetics in geographically structured populations: defining, estimating and interpreting $\mathrm{F}_{\mathrm{ST}}$. Nature Reviews. Genetics 10: 639-650.

Jordan, S.A. \& Humphries, P. 1994. Single nucleotide polymorphism in exon 2 of the BCP gene on 7q31-q35. Human Molecular Genetics 3: 1915.

Kalia, R.K., Rai, M.K., Kalia, S., Singh, R. \& Dhawan, A.K. 2010. Microsatellite markers: an overview of the recent progress in plants. Euphytica 177: 309-334.

Klink, C.A. \& Machado, R.B. 2005. Conservation of the Brazilian Cerrado. Conservation Biology 19: 707-713.

Lacerda, D.R., Acedo, M.D., Filho, J.P. \& Lovato, M.B. 2001. Genetic diversity and structure of natural populations of Plathymenia reticulata (Mimosoideae), a tropical tree from the Brazilian Cerrado. Molecular Ecology 10: 1143-1152.

Lewis, G.P., Schrire, B., Mackinder, B. \& Lock, M. 2005. Legumes of the World. Royal Botanic Gardens, Kew.

Lima, A., Silva, A.M.O., Trindade, R.A., Torres, R.P. \& Mancini-Filho, J. 2007. Composição química e compostos bioativos presentes na polpa e na amêndoa do pequi (Caryocar brasiliense Camb.). Revista Brasileira de Fruticultura 29: 695-698.

Lima, J.S., Collevatti, R.G., Soares, T.N., Chaves, L.J. \& Telles, M.P.C. 2014. Fine-scale genetic structure in Tibouchina papyrus (Pohl) Toledo (Melastomataceae), an endemic and habitat-restricted species from Central Brazil. Plant Systematics and Evolution 301: 1207-1213.

Lima, R.A.F., Rando, J.G. \& Barreto, K.D. 2015. Composição e diversidade no cerrado do leste de Mato Grosso do Sul, Brasil. Revista Árvore 39: 9-24.

Litt, M. \& Luty, J.A. 1989. A hypervariable microsatellite revealed by in vitro amplification of a dinucleotide repeat within the cardiac muscle actin gene. American Journal of Human Genetics 44: 397-401.

Machado, F.A. \& Zaher, H. 2010. Pitfalls of artificial grouping and stratification of scientific journals based on their Impact Factor: a case study in brazilian zoology. Zoologia 27: 493-502.

Medeiros, H., Amorim, A.M.A. 2016. Caryocaraceae in Lista de Espécies da Flora do Brasil. Jardim Botânico do Rio de Janeiro. Disponivel em http://floradobrasil. jbrj.gov.br/jabot/floradobrasil/FB6688 (acesso em 18-I-2016). 
Méio, B.B., Freitas, C.V., Jatobá, L., Silva, M.E.F., Ribeiro, J.F. \& Henriques, R.P.B. 2003. Influência da flora das florestas Amazônica e Atlântica na vegetação do cerrado sensu stricto. Revista Brasileira de Botânica 26: 437-444.

Melo Júnior, A.F., Carvalho, D., Póvoa, J.S.R. \& Bearzoti, E. 2004. Estrutura genética de populações naturais de pequizeiro (Caryocar brasiliense Camb.). Scientia Forestalis 66: 56-65.

Melo Júnior, A.F., Carvalho, D., Vieira, F.A. \& Oliveira, D.A. 2012. Spatial genetic structure in natural populations of Caryocar brasiliense Camb. (Caryocareceae) in the North of Minas Gerais, Brazil. Biochemical Systematics and Ecology 43: 205-209.

Mendonça, R.C., Felfili, J.M., Walter, B.M.T., SilvaJunior, M.C., Rezende, A.V., Filgueiras, T.S., Nogueira, P.E. \& Fagg, C.W. 2008. Flora vascular do bioma Cerrado: checklist com 12.356 espécies. In: S.M. Sano, S.P. Almeida, \& J.F. Ribeiro (eds.). Cerrado: ecologia e flora. Embrapa Cerrados, v. 2, Planaltina.

Mendonça, P.C., Bertoni, B.W., Amui, S.F., Corrêa, V.S.C., França, S.C. \& Pereira, A.M.S. 2012. Genetic diversity of Stryphnodendron adstringens (Mart.) Coville determined by AFLP molecular markers. Biochemical Systematics and Ecology 41: 16-20.

Moura, I.O., Gomes-Klein, V.L., Felfili, J.M. \& Ferreira, H.D. 2010. Diversidade e estrutura comunitária de cerrado sensu stricto em afloramentos rochosos no parque estadual dos Pireneus, Goiás. Revista Brasileira de Botânica 33: 455-467.

Myers, N., Mittermeier, R.A., Mittermeier, C.G., Fonseca, G.A.B. \& Kent, J. 2000. Biodiversity hotspots for conservation priorities. Nature 403: 853-858.

Nabout, J.C., Bini, L.M. \& Diniz-filho, J.A.F. 2010. Global literature of fiddler crabs, genus $U c a$ (Decapoda, Ocypodidae): trends and future directions. Iheringia. Série Zoologia 100: 463-468.

Nabout, J.C., Oliveira, G., Magalhães, M.R., Terribile, L. C. \& Almeida, F.A.S. 2011. Global climate change and the production of "Pequi" Fruits (Caryocar brasiliense) in the Brazilian Cerrado. Natureza \& Conservação 9: 55-60.

Ouborg, N.J., Piquot, Y. \& Van Groenendael, J.M. 1999. Population genetics, molecular markers and the study of dispersal in plants. Journal of Ecology 87: 551-568.

Paran, I. \& Michelmore, R.W. 1993. Development of reliable PCR-based markers linked to downy mildew resistance genes in lettuce. Theoretical and Applied Genetics 85: 985-993.

Pendlebury, D.A. 2009. The use and misuse of journal metrics and other citation indicators. Archivum Immunologiae et Therapiae Experimentalis 57: 1-11.

Penteado-Filho, R.C. 2009. O problema não é o mérito dos periódicos. Boletim da Sociedade Brasileira de Mastozoologia 54: 10-11.
Prado, L.C.S., Silva, D.B., Oliveira-Silva, G.L., Hiraki, K.R.N., Canabrava, H.A.N. \& Bispo-Da-silva, L.B. 2014. The gastroprotective effects of Eugenia dysenterica (Myrtaceae) leaf extract: the possible role of condensed tannins. Biological and Pharmaceutical Bulletin 37: 722-730.

Ribeiro, J.F. \& Walter, B.M.T. 1998. Fitofisionomias do Bioma Cerrado. In: S.M. Sano, \& S.P. Almeida (eds.). Cerrado: Ecologia e Flora. Planaltina, Embrapa CPAC, pp. 89-166.

Ribeiro, J.F. \& Walter, B.M.T. 2008. As principais fitofisionomias do Bioma Cerrado. In: S.M. Sano, S.P. Almeida, J.F. Ribeiro (eds.). Cerrado: Ecologia e Flora. Brasília, Embrapa Cerrados, pp. 151-212.

Rode, S.M. 2010. Change the QUALIS criteria! Brazilian Oral Research 24: 131-133.

Savolainen, O. \& Pyhäjärvi, T. 2007. Genomic diversity in forest trees. Current Opinion in Plant Biology 10: $162-167$.

Schlötterer, C. 2004. The evolution of molecular markers-just a matter of fashion? Nature Reviews. Genetics 5: 63-69.

Silva, A.V.C., Santos, A.R.F., Wickert, E., Silva Júnior, J.F. \& Costa, T.S. 2011. Divergência genética entre acessos de mangabeira (Hancornia speciosa Gomes). Revista Brasileira de Ciências Agrárias 6: 572-578.

Silva, J.S. \& Felfili, J.M. 2012. Floristic composition of a conservation area in the Federal District of Brazil. Brazilian Journal of Botany 35: 385-395.

Soares, T.N., Chaves, L.J., Telles, M.P.C., Diniz-Filho, J.A.F. \& Resende, L.V. 2008a. Landscape conservation genetics of Dipteryx alata ("baru" tree: Fabaceae) from Cerrado region of central Brazil. Genetica 132: 9-19.

Soares, T.N., Chaves, L.J., Telles, M.P.C., Diniz-Filho, J.A.F. \& Resende, L.V. 2008b. Distribuição espacial da variabilidade genética intrapopulacional de Dipteryx alata. Pesquisa. Agropecuária Brasileira 43: 1151-1158.

Soares, T.N., Melo, D.B., Resende, L.V., Vianello, R.P., Chaves, L.J., Collevatti, R.G. \& Telles, M.P.C. 2012. Development of microsatellite markers for the neotropical tree species Dipteryx alata (Fabaceae). American Journal of Botany 99: 5-6.

Soares, A.A.V, Santos, A.M., Carvalho, D. \& Rosado, S.C.S. 2014. Genetic Variability of Dipteryx alata Vog. (Fabaceae) in a Provenance and Progeny Trial. Australian Journal of Basic and Applied Sciences 8: 169-175.

Soares, T.N., Diniz-Filho, J.A.F., Nabout, J.C., Telles, M. P.C., Terribile, L.C. \& Chaves, L.J. 2015. Patterns of genetic variability in central and peripheral populations of Dipteryx alata (Fabaceae) in the Brazilian Cerrado. Plant Systematics and Evolution 301: 1315-1324.

Tarazi, R., Moreno, M.A., Gandara, F.B., Ferraz, E.M., Moraes, M.L.T., Vinson, C.C., Ciampi, A.Y., Vencovsky, R. \& Kageyama, P.Y. 2010. High levels of genetic differentiation and selfing in the Brazilian cerrado fruit tree Dipteryx alata Vog. (Fabaceae). Genetics and Molecular Biology 33: 78-85. 
Telles, M.P.C., Silva, R.S.M., Chaves, L.J., Coelho, A.S.G. \& Diniz-Filho, J.A.F. 2001. Divergência entre subpopulações de cagaiteira (Eugenia dysenterica) em resposta a padrões edáficos e distribuição espacial. Pesquisa Agropecuária Brasileira 36: 1387-1394.

Telles, M.P.C., Coelho, A.S.G., Chaves, L.J., DinizFilho, J.A.F. \& Valva, F.D. 2003. Genetic diversity and population structure of Eugenia dysenterica DC. ("cagaiteira" - Myrtaceae) in Central Brazil: Spatial analysis and implications for conservation and management. Conservation Genetics 4: 685-695.

Telles, M.P.C., Silva, J.B., Resende, L.V., Vianello, R.P., Chaves, L.J., Soares, T.N. \& Collevatti, R.G. 2013. Development and characterization of new microsatellites for Eugenia dysenterica DC (Myrtaceae). Genetics and Molecular Research 12: 3124-3127.

Telles, M.P.C., Dobrovolski, R., Souza, K.S., Lima, J.S., Collevatti, R.G., Soares, T.N., Chaves, L.J. \& DinizFilho, J.A.F. 2014. Disentangling landscape effects on population genetic structure of a Neotropical savanna tree. Natureza \& Conservação 12: 65-70.

Trindade, M.G. \& Chaves, L.J. 2005. Genetic structure of natural Eugenia dysenterica DC (Myrtaceae) populations in northeastern Goiás, Brazil, accessed by morphological traits and RAPD markers. Genetics and Molecular Biology 28: 407-413.

Vedel, F., Quetier, F. \& Bayen, M. 1976. Specific cleavage of chloroplast DNA from higher plants by EcoRI restriction nuclease. Nature 263: 440-442.

Vos, P., Hogers, R., Bleeker, M., Reijans, M., Van de Lee, T., Hornes, M., Friters, A., Pot, J., Paleman, J., Kuiper, M. \& Zabeau, M. 1995. AFLP: A new technique for DNA fingerprinting. Nucleic Acids Research 23: 4407-4414.

Anexo 1. 171 publicações encontradas na área de genética de populações envolvendo as espécies de plantas do Cerrado, entre os anos de 1999 à 2014.

Abreu et al. 2012. Genetics and Molecular Biology 35: 119-121; Antiqueira et al. 2014. Genetica 142:11-21; Antiqueira et al. 2014. Revista Árvore 38: 667-675; Assis et al. 2013. Genetics and Molecular Research 12: 3500-3509; Baldauf et al. 2011. American Journal of Botany 98: E244-E246; Baldauf et al. 2013. Forest Ecology and Management 310: 434-441; Baldauf et al. 2014. Conservation Genetics 15:1073-1083; Barbosa et al. 2010. Genetics and Molecular Research 9: 695-704; Barbosa et al. 2012. American Journal of Botany 99: 1477-1488; Barbosa et al. 2013. Brazilian Journal of Botany 36: 179-187; Barreira et al. 2006. Scientia Forestalis 71: 119-130; Batistini et al. 2009. Genetics and Molecular Research 8: 52-63; Bellon et al. 2007. Revista Brasileira de Fruticultura 29: 124-127; Bellon et al. 2009. Revista Brasileira de Fruticultura 31:
Wainer, J. \& Vieira P. 2013. Correlations between bibliometrics and peer evaluation for all disciplines: the evaluation of Brazilian scientists. Scientometrics 96: 395-410.

Williams, J.G.K., Kubelik, A.R., Livak, K.J., Rafalski, J.A. \& Tingey, S.V. 1990. DNA polymorphisms amplified by arbitrary primers are useful as genetic markers. Nucleic Acids Research 18: 6531-6535.

Zietkiewics, E., Rafalski, A. \& Labuda, D. 1994. Genome fingerprint by sequence repeat (SSR)-anchored polymerase chain reaction amplification. Genomics 20: 176-183.

Zimmermam-Franco, D.C., Bolutari, E.B., Polonini, H.C., Carmo, A.M.R., Chaves, M.G.A.M. \& Raposo, N.R.B. 2013. Antifungal activity of Copaifera langsdorffii desf oleoresin against dermatophytes. Molecules 18: 12561-12570.

Zucchi, M.I., Brondani, R.P.V., Pinheiro, J.B., Brondani, C. \& Vencovsky, R. 2002. Transferability of microsatellite markers from Eucalyptus spp. to Eugenia dysenterica (Myrtaceae family). Molecular Ecology Notes 2: 512-513.

Zucchi, M.I., Brondani, R.P.V., Pinheiro, J.B., Chaves, L.J., Coelho, A.S.G. \& Vencovsky, R. 2003. Genetic structure and gene flow in DC in the Brazilian Cerrado utilizing SSR markers. Genetics and Molecular Biology 26: 449-457.

Zucchi, M.I., Pinheiro, J.B., Chaves, L.J., Coelho, A.S.G., Couto, M.A., Morais, L.K. \& Vencovsky, R. 2005. Genetic structure and gene flow of Eugenia dysenterica natural populations. Pesquisa Agropecuária Brasileira 40: 975-980.

197-202; Bertoni et al. 2007. Scientia Agricola 64: 409-415; Bertoni et al. 2010. Genetics and Molecular Biology 33: 532-538; Bertoni et al. 2010. Horticultura Brasileira 28: 209-213; Blanco et al. 2007. Pesquisa Agropecuária Tropical 37: 169-175; Botrel \& Carvalho. 2004. Brazilian Journal of Botany 27: 621-627; Botrel et al. 2006. Revista Árvore 30:821-827; Braga et al. 2007. Molecular Ecology Notes 7: 53-56; Braga \& Collevatti. 2011. Heredity 106: 911-919; Bressan et al. 2012. American Journal of Botany 99: E237-E239; Buttow et al. 2010. Revista Brasileira de Fruticultura 32: 230-239; Buzzatti et al. 2014. Biochemical Systematics and Ecology 56: 75-79; Caddah et al. 2013. Plant Systematics and Evolution 299:731-741; Caetano et al. 2008. Molecular Ecology 17: 3147-3159; Carvalho et al. 2010. Brazilian Journal of Botany 33: 599-606; Carvalho et al. 2012. Revista Brasileira de Fruticultura 34: 227-233; Cavallari et al. 2010. Annals of Botany 106: 627-636; Cerqueira-Silva et al. 2012. American Journal of Botany 99: 
E170-E172; Ciampi et al. 2008. Molecular Ecology Resources 8: 1074-1077; Collevatti et al. 1999. Heredity 83: 748-756; Collevatti, et al. 2001a. Molecular Ecology 10: 349-356; Collevatti et al. 2001b. Heredity 86: 60-67; Collevatti et al. 2003. Molecular Ecology 12: 105-115; Collevatti et al. 2010. Tree genetics \& genomes 6 :555-564; Collevatti \& Ray. 2011. Journal of Ecology 99: 757-763; Collevatti et al. 2012. Ecology and Evolution 2: 1024-1035; Collevatti et al. 2013. Heredity 111: 97-105; Collevatti et al. 2013. Plant systematics and evolution 300:1719-1727; Collevatti et al. 2014. BMC Evolutionary Biology 14:213; Collevatti et al. 2014. Plant systematics and evolution 300:1671-1681; Costa et al. 2011. Pesquisa Agropecuária Brasileira 46: 499-508; Costa et al. 2012. Genetics and Molecular Research 11: 2338-2342; Cota et al. 2011. Genetics and Molecular Research 10: 2172-2180; Cota et al. 2012. Genetics and Molecular Research 11: 4609-4616; Cruz et al. 2012. American Journal of Botany 99: E210-E212; Damasceno et al. 2011. Genetics and Molecular Research 10: 1180-1187; Defavari et al. 2009. Scientia Forestalis 37: 089-098; Estopa et al. 2006. Scientia Forestalis 70: 97-106; Feres et al. 2009. Genetic Resources and Crop Evolution 56: 797-807; Feres et al. 2009. Molecular Ecology Resources 9: 434-437; Feres et al. 2012. American Journal of Botany 99: E154-E156; Feres et al. 2012. Conservation Genetics 13: 393-405; Ferreira-Ramos et al. 2008. Conservation Genetics 9: 1281-1285; Fioravante et al. 2009. Revista Árvore 33: 265-275; Franceschinelli \& Bawa. 2005. Brazilian Journal of Botany 28: 163-170; Franceschinelli et al. 2006. Annals of Botany 97: 585-592; Franzon et al. 2010. Revista Brasileira de Fruticultura 32: 240-250; Freitas et al. 2004. Genetics and Molecular Biology 27: 425-431; Freitas et al. 2008. Genetics and Molecular Research 7: 388-398; Gaino et al. 2011. Brazilian Journal of Botany 34: 545-551; Gaiotto et al. 2001. Molecular Ecology Notes 1:86-88; Gaiotto et al. 2003. Journal of Heredity 94: 399-406; Giudice-Neto \& Kageyama. 2000. Brazilian Journal of Botany 23: 207-215; Glasenapp et al. 2012. Brazilian Journal of Botany 35:137-144; Glasenapp et al. 2014. Revista Árvore 38: 103-112; Glasenapp et al. 2014. Revista Brasileira de Plantas Medicinais 16: 216-224; Goncalves et al. 2010. Revista Árvore 34: 95-101; Gonçalves et al. 2010. Brazilian Journal of Botany 33: 325-332; GoncalvesAlvim et al. 2004. Annals of Botany 94: 259-268; Guidugli et al. 2009. Conservation Genetics 10: 1001-1004; Guidugli et al. 2012. Genetics and
Molecular Research 11: 10-16; Jaeger et al. 2007. Cerne 13: 200-207; Jaeger et al. 2007. Scientia Forestalis 73: 91-99; Jesus et al. 2001. Plant Systematics and Evolution 226: 59-68; Jesus et al. 2009. Plant Systematics and Evolution 277: 187-196; Junqueira et al. 2007. Revista Brasileira de Fruticultura 29: 571-575; Junqueira et al. 2010. Revista Brasileira de Fruticultura 32: 840-846; Kamada et al. 2009. Acta Scientiarum 31: 403-409; Kawaguici \& Kageyama. 2001. Scientia Forestalis 59: 131-143; Lacerda et al. 2001. Molecular Ecology 10: 1143-1152; Lacerda et al. 2002. Plant Systematics and Evolution. 235: 67-77; Lanes et al. 2014. Journal of Heredity 106: 102-112; Lima et al. 2011. Genetics and Molecular Research 10: 2893-2904; López-Roberts et al. 2013. Applications in Plant Sciences 1: 1300015; Lousada et al. 2011. Genetica 139: 431-440; Lousada et al. 2013. Brazilian Journal of Botany 36: 45-53; Martins et al. 2006. Conservation Genetics 7: 957-969; Martins et al. 2008. Brazilian Journal of Botany 31: 61-69; Martins et al. 2011. Genetics and Molecular Research 10: 665-677; Martins et al. 2012. American Journal of Botany 99: e289-e291; Martins et al. 2012. Revista Brasileira de Fruticultura 34: 1143-1153; Medri et al. 2011. Genetics and Molecular Research 10: 1084-1091; Medri et al. 2011. Genetics and Molecular Research 10: 3186-3198; Melo et al. 2009. Acta Botanica Brasilica 23: 259-266; Melo et al. 2012. Biochemical Systematics and Ecology 43: 205-209; Melo-Júnior et al. 2004. Scientia Forestalis. 66: 56-65; Mendonça et al. 2012. Biochemical Systematics and Ecology 41: 16-20; Mendonça et al. 2014. International Journal of Forestry Research 1: 1-8; Menezes et al. 2012. Genetics and Molecular Research 11: 4058-4062; Moraes et al. 2005. Revista Árvore 29: 281-289; Moraes et al. 2007. Scientia Forestalis 74: 75-86; Moreira et al. 2012. Genetics and Molecular Research 11:3729-3734; Moreno et al. 2009. Scientia Forestalis 37: 513-523; Moura et al. 2009. Scientia Forestalis 37: 143-1; Moura et al. 2011. Acta Botanica Brasilica 25: 937-940; Moura et al. 2011. Bioscience Journal 3: 473-481; Moura et al.2012. Genetics and Molecular Research 11: 2674-2682; Moura et al. 2013. Genetics and Molecular Research 12: 6006-6010; Mühlen et al. 2013. Journal of the Society for the Anthropology of Lowland South America 11: 66-73; Novaes et al. 2010. Molecular Ecology 19: 985-998; Novaes et al. 2013. Plos One. 8: e82198; Nucci et al. 2008. Molecular Ecology Resources 8: 224-226; Oliveira et al. 2008. Revista Árvore. 32: 355-363; Oliveira et al. 2012. American Journal of Botany 99: e391-e393; Oliveira 
et al. 2012. Genetics and Molecular Research 1: 531-538; Pereira et al. 2007. Botanical Journal of the Linnean Society 153: 401-416; Pereira et al. 2008. Molecular Ecology Resources 8: 1329-1331; Pinheiro et al. 2013. Evolution 67: 2024-2039; Pinto et al. 2004. Scientia Forestalis 65: 40-48; Rabelo et al. 2011. Conservation Genetics Resources 3: 741-743; Ramos et al. 2007. Annals of Botany 100: 1219-1228; Ramos et al. 2009. Journal of Heredity 100: 206-216; Reis \& Grattapaglia. 2004. Genetic Resources and Crop Evolution 51: 529-538; Ribeiro et al. 2014. Brazilian Journal of Botany 37: 353-356; Ritter et al. 2012. American Journal of Botany 99: E97-E98; Rosado et al. 2010. Crop Science 50: 2372-2382; Ruas et al. 2009. Conservation Genet Resources 1:245-248; Ruas et al. 2011. Biologia Plantarum 55: 396-399; Santos et al. 2009. Conservation Genetics Resources 1:481-485; Santos et al. 2009. Molecular Ecology Resources 9: 192-194; Santos et al. 2010. Crop Breeding and Applied Biotechnology 10: 364-369; Santos-Garcia et al. 2011. Euphytica. 178: 185-193; Santos-Garcia et al. 2012. Genetics and Molecular Biology 35: 847-861; Sebben et al. 2003. Scientia Forestalis 106: 134-145; Silva et al. 2004. Scientia Forestalis 66: 94-99; Silva et al. 2011. Cerne 17: 195-201; Silva et al. 2011. Revista Brasileira de Ciências Agrárias 6: 572-578; Silva et al. 2012. Tropical and Subtropical Agroecosystems 15: 217-225; Silva et al. 2013. Biochemical Systematics and Ecology 51: 189-194; Silva et al. 2013. Revista Brasileira de Fruticultura 35: 1093-1100; Siqueira et al. 2009. Genetics and Molecular Biology 32:
104-110; Siqueira et al. 2010. Biochemical Genetics 48: 9-10; Soares et al. 2008. Genetica 132: 9-19; Soares et al. 2008. Pesquisa Agropecuária Brasileira 43: 1151-1158; Soares et al. 2012. American Journal of Botany 99: e72-e73; Soares et al. 2013. Genetics and Molecular Research 12: 3146-3149; Soares et al. 2014. Australian Journal of Basic and Applied Sciences 8: 169-175; Sousa et al. 2009.Conservation Genetics Resources 1: 347-352; Souza et al. 2007. Cerne 13: 239-247; Souza et al. 2012. American Journal of Botany 99: e102-e104; Tarazi et al. 2010. Genetics and Molecular Biology 33: 78-85; Tarazi et al. 2013a. Ecology and Evolution 3: 1003-1015; Tarazi et al. 2013b. Heredity 110: 578-585; Telles et al. 2001. Pesquisa Agropecuária Brasileira 36: 1387-1394; Telles et al. 2003. Brazilian Journal of Botany 26: 123-129; Telles et al. 2003. Conservation Genetics 4: 685-695; Telles et al. 2010. Brazilian Journal of Botany 33: 291-300; Telles et al. 2011. Genetics and Molecular Research 10: 321-325; Telles et al. 2013. Genetics and Molecular Research 12: 3124-3127; Telles et al. 2014. Natureza \& Conservação 12:65-70; Trindade \& Chaves. 2005. Genetics and Molecular Biology 28: 407-413; Viana e Souza \& Lovato. 2010. Biochemical Systematics and Ecology 38: 49-56; Vieira et al. 2010. Ciência Rural 40: 2467-2471; Vieira et al. 2011. Crop Breeding and Applied Biotechnology 11: 232-240; Vieira et al. 2010. Revista Brasileira de Ciências Agrárias 5: 219-224; Zucchi et al. 2003. Genetics and Molecular Biology 26: 449-457; Zucchi et al. 2002. Molecular Ecology Notes 2: 512-513; Zucchi et al. 2005. Pesquisa Agropecuária Brasileira 40: 975-980. 